\title{
MAKING ENGLISH A NEW LATIN
}

\section{SYLWIA SCHEUER}

sylwia_scheuer@yahoo.fr

Université de Paris 3

\begin{abstract}
The paper looks at various aspects of the so-called Latin-English analogy and particularly at the ways in which English may share the fate of Latin in ultimately becoming a victim of its own success. A critical factor in the history of Latin was a conceptual split between its native and non-native varieties, which eventually proved instrumental in establishing its reputation as a dead language. The author wishes to argue that current proposals for a codification of English as a Lingua Franca, aimed at providing vast numbers of L2 learners with a pedagogical alternative that does not emulate L1 standards, may be regarded as major steps towards making English a new Latin: creating a similar split between native versus foreigners' English.
\end{abstract}

Key words: Latin analogy, ELF, ELT, standards

\section{Introduction}

"There is a growing concern about endangered languages but very little debate about the management of large languages, of which English is the largest". Graddol's (1997: 63) statement outlines one of the many paradoxes which surround the vast expansion of English and its unprecedented success as the language of international communication. Recent emphasis has been both on its pivotal role in promoting social inequalities ("linguistic imperialism") and on its widespread use as a neutral, composite lingua franca, jointly owned by all its users and therefore free from connotations of cultural imperialism. Volumes have been written on how profoundly English has changed the world in general, and the global linguistic scene in particular, but much less attention has been devoted to how the world is changing English.

The position of global dominance that English currently occupies is often compared to the role once played by Latin, which for many centuries served as the international language of Western civilisation, and was hence learnt and spoken by vast populations of both native and non-native speakers. The so-called Latin-English analogy, which has been a recurring motif in recent applied linguistics literature, can be sought on a number of different planes. The history of both languages presents a similar route from humble beginnings, marked by inferiority complex, to spectacular success, marked by boastful glorification. Just like Latin experienced a sense of inferiority to the Greek language and culture (Farrell 2001), so did English initially grow in the shadow of French and Latin (e.g. Baugh and Cable 2002, Fisiak 2000). Latin and English each went on to serve as the lingua franca of a vast empire that expanded over a few continents, killing off other 
languages in the process. The spread of Latin, which went hand in hand with the Roman administration, was regarded as "taking civilised speech to the rest of the world" (Farrell 2001: 1), a statement which would hold equally true for the progress of English, which accompanied the expansion of the British rule. Both imperial languages later spreadwith broadly understood cultural assets-even to countries that had never been situated within the political or linguistic realm of the respective empires.

It is only natural that questions should be raised as to whether English may share the fate of Latin in ultimately becoming a victim of its own success. In the wake of the "globalisation" of Latin came a multiplication of regional varieties, as well as a steady influx of foreign influence, which-coupled with adverse political developmentsgradually transformed the classical tongue into several daughter languages. Since, as the common understanding of history has it, the widespread success and popularity of Latin did not guarantee its survival as a living language (e.g. Crystal 1997: 7), it is hardly surprising that various scholars have explored the notion that English may also split into a number of independent and mutually unintelligible languages, thus becoming "dead" in the Latin sense. However, a fact that is often lost from sight is that the kind of Latin that conquered the Western world in the Early Middle Ages was foreigners' Latin, which had previously parted company with the natural continuations of the ancient Romans' mother tongue. The split between the native and non-native varieties happened in the wake of the spelling and pronunciation reforms instigated by Charlemagne at the end of the $8^{\text {th }}$ century. Paradoxically, it was precisely the latter-the learned, and to a large extent artificial, entity-that preserved the original name, thereby vitally contributing to Latin's established reputation as a dead language, in spite of its Modern Romance continuations being still alive and well (e.g., Wright 2002 and 2004). The main point that I wish to argue here is that while the mechanisms underlying the operation of the two world languages are crucially different, native and non-native Englishes might also, in the future, take divergent routes of development. This may happen if the linguistic forms taught to foreign learners deliberately ignore L1 usage, particularly if English as a Lingua Franca (ELF) becomes codified along non-native lines. Indeed, the need for making ELF a viable pedagogic alternative has been much emphasised in recent years, and intensive work on a fully-fledged ELF model, based solely on patterns of interaction among non-native speakers of English, is well under way (e.g. Jenkins 2000 and 2007; Seidlhofer 2006). If successful, such schemes may pave the way for a conceptual separation, and consequently a future split, between international and native English(es), thereby making the fate of English similar to that of Latin in yet another way.

The following sections will present certain aspects of the Latin-English analogy, with a view to obtaining certain clues as to the possible future development of the modern lingua franca. In particular, parallels will be drawn between the actual, likely, or hypothetical fate of English and the fortunes of Latin as (1) a "dead" language; (2) an international language that eventually declined in importance; and (3) a language with clearly divergent native and non-native varieties. Special attention will be devoted to aspect (3), which is probably the least prevalent, and the most speculative, of the three. 


\section{A 'dead' language}

A popular misconception about the story of Latin seems to be that it died in the classic sense of language death: by gradually losing domains and speakers due to a switch to another language on the part of younger generations. This is illustrated by the following quotation from Mackey (2003: 78): "For long after the last of its native speakers had died, the Latin language continued to expand as a written language far beyond the borders of the Roman Empire". Even if statements like these are just mental shortcuts, they are still representative of the widespread "Latin-died-one-day" thinking. A better insight into Latin's demise is afforded by viewing it as eventual disintegration into mutually unintelligible accents and dialects, which ties in with Dressler's (1996: 195) notion that

[a] language may also perish by being continuously transformed into a daughter language

/.../ then we may speak of a dead language /.../ but preferably not of language death.

Consequently, we may say that in a slightly abstract sense, Latin did die with its last native speakers, when these were no longer considered speakers of Latin, but rather Romance.

There is neither a need nor space here to provide a detailed account of why, how and when Latin evolved into Romance, so I will limit myself to certain crucial points which bear potential relevance to the English analogy theme. The first explicit mention of the Romance, rather than Latin, language in post-Roman Gaul is dated to the Council of Tours (AD 813), where it was proclaimed that priests should deliver their sermons "in rusticam Romanam linguam aut theotiscam". The official arrival of the "new" tongue did not, however, automatically mean its fragmentation into respective Romance languages; according to Wright (2002) the conceptual distinctions between those were only made when standard languages were constructed, and this did not occur until the $12^{\text {th }} / 13^{\text {th }} \mathrm{c}$.

While there are no objectively identifiable points in development when two varieties actually become two different languages, it is sometimes relatively easy to pinpoint the moment when they stop being regarded as instances of one and the same linguistic system. In fact, one may be synonymous with the other: the only true delimitation of two varieties belonging together may be the speakers' perceptions. As Chambers and Trudgill (1998: 4) point out, "paradoxically enough, a 'language' is not a particularly linguistic notion at all"; what matters greatly are

distinct, codified, standardised forms, with their own orthographies, grammar books, and literatures; that they correspond to /.../ separate nation states; and that their speakers consider that they speak different languages.

Speakers' perceptions, however, can be manipulated, and may sometimes undergo radical transformations that can be traced back to certain historic events, or even arbitrary decisions taken by those in power.

According to Wright (2002 and 2004), whose perspective I adopt in this paper, the conceptual distinction between Latin and Early Romance in the $9^{\text {th }} \mathrm{c}$. Gaul was an accidental and artificial outcome of reforms undertaken during the so-called Carolingian 
Renaissance. The historic moment which marked the onset of the split came when Charlemagne appointed an Englishman, Alcuin of York, to reform education and systematise orthography. Alcuin, "appalled at the condition to which the language has descended among native speakers" (Farrell 2001: 16), instituted a radical reform of the official reading pronunciation of the Church. As a result, it was decreed that Latin texts should be read out as if they represented phonetic script, by giving a separate sound to every single written letter. This was common practice in Alcuin's native Britain, where Latin was learned as a foreign language, but no longer the case in a native speaker country like Gaul. As Wright (2002: 125) points out, this was tantamount to the creation of a bilingual situation almost overnight, in that a divide was established between reformed Latin (which has continued as a learned language ever since), accessible only to the educated minority, and the one that was actually used and understood by the unschooled masses inhabiting Charlemagne's realm at the time (Early Romance).

Alcuin's reforms had enormously far-reaching consequences, although their impact was not immediately apparent. Wright (2004: 5 and 11) stresses the fact that the Carolingian Reforms acted as a catalyst for divergent evolution of the particular Romance dialects. Alcuin's purification of Merovingian Latin prompted attempts to write down Gallo-Roman phonetically (as the traditional spelling was now reserved for the reformed pronunciation), producing written forms which proved useless to Romance readers outside Gaul. This, in turn, inspired analogous experiments with phonetic spellings in the other Latin-derived varieties, which now gradually acquired their separate names. The elaboration of divergent written patterns, together with divergent labels for the individual Latin mutations, catalysed the perceptual split among the particular Romance incarnations, the variation between which ceased to be regarded as simply language-internal. Hence, Charlemagne's language policy may be held responsible not only for the conceptual separation of Latin and Romance, but also for the consequent fragmentation of Romance into various national languages. In Wright's opinion, neither of these developments was inevitable.

The dissolution-into-mutually-unintelligible-varieties theme figures prominently among anxieties expressed by those concerned about the future of English, who are worried that "[j]ust as Latin, which once held sway over a great linguistic empire, split into French, Italian, Spanish, Portuguese and Romanian /.../ so may the future of English be not as a single language but as the parent of a family of languages" (Bragg 2004: 309). Firm predictions about British and American English drifting away beyond the threshold of sameness have been made at least since the end of the $18^{\text {th }}$ century, when the notion of the "American language" fitted in perfectly with the ideology accompanying the birth of a new nation. It is perhaps tempting to say that the gloomy prophecies of a forthcoming split go, as yet, unfulfilled: the two major Inner Circle varieties of English still are, after all, instances of one linguistic entity, and will remain so in the foreseeable future, thanks to the restraining influence of electronic communication and mass media. This seems to be the major argument put forward by those linguists who question the validity of using analogies with Latin to gain insights into the future of English, as

the primary condition for the development of Vulgar Latin into neo-Latin or Romance languages, namely the paucity of daily contact among their speakers, no longer holds true (Rajagopalan 2009: 53). 
However, two crucial questions present themselves at this point. Firstly, isn't the role of the modern means of communication overrated? Even though regular exposure to other varieties promotes mutual intelligibility, it certainly does not ensure broad uniformity (especially at the level of phonology), as it has been repeatedly proven that listeners do not generally copy the speech habits of their fellow native speakers from mass media (e.g., Milroy 2001, Trudgill 2001). If they did, all the English-speaking inhabitants of the global village would now be participating in a process of dialect levelling, whereas precisely the reverse has been observed e.g., for the vowel systems of British (especially southern) and American (especially northern) English, which are currently undergoing changes in opposite directions (Trudgill 2002). Secondly, how do we know that British and American English(es) have not become separate languages already? Or, should they do so one day, how will we know? Mutual intelligibility is obviously a crucial, but definitely not an overriding, factor in these considerations: sociolinguistics manuals offer numerous examples of varieties which are perfectly intelligible, but are nonetheless regarded as separate languages (e.g., Scandinavian languages), and vice versa (e.g., Mandarin and Cantonese as dialects of Chinese). One may invoke Chambers and Trudgill's (1998) views, quoted previously, and say that what keeps the variation intra(rather than inter-) lingual is shared political history, cultural tradition, a common written standard, and-above all-lack of political will to claim otherwise. The fact that British and American are not regarded as different languages is due not so much-or at least not exclusively-to linguistic similarity, but rather to the common perception of them as instantiations of a single system. It is also worth reiterating that those perceptionsinformed by the para- and extralinguistic factors mentioned above-can be deftly manipulated.

It would border on the whimsical to suggest that language reforms à la Alcuin and Charlemagne, whereby native speakers are made to radically change their pronunciation habits, would stand a chance of being introduced, let alone successfully, nowadays. The patterns of spoken L1 usage are rather immune to extrinsically controlled language engineering. What is more readily susceptible to state control, however, is the authorised writing system of a country, which could become the object of drastic top-down shakeups within a relatively short period of time. Let us consider the following, grossly simplified, scenario: in a bid to facilitate the acquisition of spelling by the future generations, the UK government decides to thoroughly revise the official British English orthography, so as to bring it into rough conformity with the current pronunciation. For example, a word like $<$ water $>$ will now be spelt $<$ wote $>$. In view of these developments the representatives of the other major native speaker countries, who do not want to lag behind, undertake similar reforms, in order to make their spelling more or less phonographic, as well. For example, in the USA <water> will now be replaced by $<$ wader $>$. Under these circumstances, it would be virtually impossible to claim that the British and American varieties still represent one and the same language, for a number of reasons. An Englishman would not be able to read an American publication without special schooling, so all books, manuals, etc., would have to be targeted at one or the other speech community. A foreigner wishing to learn "English" would have to make a careful choice between the two varieties right at the outset of the learning process, as literary proficiency in one would not enable him to function in the other. As a concomitant of the radical spelling reforms, new names for the two systems would gain 
currency (or at least the unifying adjective "English" would sink into oblivion, resulting in the two languages being called simply British and American), in order to facilitate, and at the same time greatly enhance, the distinction. In other words, the above scenario provides a recipe for English-as we conceive of it today-becoming dead almost overnight.

It stands to reason that such fateful decisions to elaborate significantly different written standards for the major varieties of English are very unlikely to be made at present: it is difficult to imagine any compelling reason why a government should be willing to incur the enormous cost and inconvenience involved in launching such a project. However, the main point I am trying to argue is that British and American Englishes could become separate tongues without a single native speaker altering their current speaking habits, that is without the language itself changing one iota. Instead of waiting for a few centuries until the two varieties naturally drift apart and evolve into distinct languages, one may simply change the way they are perceived: modify the packaging and the name on it, without necessarily changing the product inside. Pursuing the hypothetical spelling reform scenario depicted above, one could envisage the way in which future historical linguists might comment on the events. The acquisition of new, separate names by each variety would probably be described as a thoroughly natural result of the centuries-long process of their drifting away both from the language of Shakespeare (hence the loss of the label "English") and each other (hence two different labels). Needless to say, accounts like these would entirely overlook the fact that the split did not have to happen, and would not have happened (or at least not yet) but for the unfortunate and arbitrary decision to tamper with the writing systems. Add to this the fact that under the above scenario none of the native speaker countries would use the old writing system or the old name of the language anymore, so that both could now be usurped by foreign users, who develop their own-English as a Lingua Francapronunciation to go with it ... and the Latin analogy becomes complete.

\section{An international language which declined in importance}

The significance of Latin as the dominant medium of education, science, serious thought and respectable literature diminished after the Renaissance, when-after the initial revival of antiquity and the classical standards of latinity-it was gradually being displaced in favour of the vernacular languages, now allowed full scope of expression. Latin still retained a foothold in diplomacy (until the $18^{\text {th }} \mathrm{c}$.) and in European universities, where it continued as a teaching language till the late $19^{\text {th }}$ century (Orbis Latinus).

However, the use of Latin has never become confined to that of a tool vital for the study of the ancient or medieval literature, thus allowing it to enjoy an active and varied afterlife until the present day. The latest edition of Ethnologue (Lewis 2009) classifies Latin as a language of Vatican State, and offers the following information under the heading of Language Use: "National language. Used in Roman Catholic liturgy. Revival effort underway. The Vatican Latin Foundation established in 1976". One of the aims of the Foundation is the development of new vocabulary for naming the objects and concepts unknown in the ancient or medieval times. The fruit of these efforts, Lexicon Recentis Latinitatis (available on-line), features entries like "night club" (taberna 
nocturna), "playboy" (iúvenis voluptárius) or "terrorist" (tromócrates). Latin is also used in internet-based discussion groups that make it their official language of contributions: a simple search returns a sizeable number of hits like Circulus Latinus Londiniensis, Circulus Latinus Lutetiensis, Circulus Latinus Pragenus, Circulus Latinus Zagrabiensis, etc.

Nevertheless, the fact remains that Latin retired from its role as an important international language a long time ago. Among the reasons why even the learning of Latin on a massive scale has been discarded in the last few decades, Bocheński (2004: 24) lists the "technologisation" of the modern, industrial society (which marginalised the less practical, spiritual goods associated with latinity), and the collapse of Eurocentrism. The latter was previously manifested in the conviction, on the part of the Europeans, that they represented the principal source of culture, as well as the superior civilisation in general, and the only true religion in particular, all of which were invariably of Latin origin. Hence, while Latin-understood as a national language-became a victim of its own success in late antiquity, the hegemony of Latin culture ultimately succumbed to democracy in the $20^{\text {th }}$ century.

The question that naturally presents itself at this point is whether (and, if so, when and how) English may also be abandoned as the medium of international communication. Common sense suggests that "the dominance of English, like all empires, will eventually diminish" (Master (1998: 723). Graddol devoted his 1997 book to projecting the future of English by analysing the current trends in global economics, technology and culture. His conclusion was that no other single language would probably overtake English in terms of global influence, or replace it as a world lingua franca within the next 50 years. However, a gradual shift might happen from linguistic monopoly to oligopoly, formed by a small number of languages, "each with particular spheres of influence and regional basis" (Graddol 1997: 58), which would diminish the relative importance of English and thus reduce the apparently insatiable demand for it. Of profound significance in accelerating this process might be matters of public attitudes and concerns with political correctness, with their capability to override economic rationality. The dominant position of English may be threatened by various movements towards universal language rights. As a result, it would be ideologically more appropriate to switch to a regional language when securing international communication, rather than promote a linguistic killer such as English. As Graddol points out, even if a direct, causal link between the spread of English and language loss were disproved by linguists, global public opinion might remain unaffected, and the world might still turn against the convenient scapegoat, "associating it with industrialisation, the destruction of cultures, infringement of basic human rights, global cultural imperialism and widening social inequality" (1997: 62). In this way, just as Learned Latin was largely killed by democracy in the $20^{\text {th }}$ century, so can English, as we conceive of it now, ultimately fall a victim to the $21^{\text {st }} \mathrm{c}$. ultra-democratic projects.

Although in 1997 Graddol stated that there was "no imminent danger to the English language, nor to its global popularity", he added that "the next 20 years or so will be a critical time for the English language and for those who depend upon it" (1997: 2). Barely 9 years afterwards, some answers appeared already:

People have wondered for some years whether English had so much got its feet under the global office desk that even the rise of China - and Mandarin - could ever shift it from its 
position of dominance. The answer is that there is already a challenger, one which has quietly appeared on the scene whilst many native speakers of English were looking the other way, celebrating the rising hegemony of their language. The new language which is rapidly ousting the language of Shakespeare as the world's lingua franca is English itself - English in its new global form. (Graddol 2006: 11)

The ultimate menace to the language of Shakespeare may therefore be lurking behind the new, democratic concepts of English as an International Language (EIL). It is also here that the ultimate, and possibly the most fundamental, aspect of the Latin-English analogy can be sought.

\section{A Language with Distinct Native vs. Non-Native Varieties}

As the previous sections demonstrated, the distinction between Latin as a Native Language (LNL) and Latin as an International Language (LIL) arrived on the linguistic scene at the time of the Carolingian Renaissance. While LNL turned into Romance and has continued living under several different guises until the present day, LIL became a learned language, devoid of native speakers, which-having been adopted by the Churchbecame the lingua franca of the western civilisation; the universal language of education, literature, science, diplomacy, etc. It was the Alcuinian model of Latin pronunciation (derived directly from the traditional spelling) and Latin grammar that spread across and outside the Romance areas and subsequently became the basis of all education, now studied everywhere-even in the former LNL countries-as a foreign language (Wright 2002: 15). As Farrell (2001: 14f) points out, the British monk-rather than being credited with having restored classical Latin, which seemed to be his mission-can be charged with having " 'invented' medieval Latin as an artificial and mainly literary entity distinct from spoken Romance". The story becomes even more remarkable if we consider the fact that it was precisely a kind of Alcuinian Latin that ultimately became what we now consider Latin proper, assuming that it has continued uninterrupted and largely unchanged since the imperial times, with the Catholic Church as the guardian of this continuity. Pope (1953/1973: 28) observes that the lingua franca of the Middle Ages was a comfortable, easy-going kind of Latin, where new words were created independently in various countries, reflecting the influence of the local languages, as well as of the political or social conditions. The obvious question is whether and how English may share this aspect of Latin's fate.

The observation that the ELT scene at the beginning of the new millennium presents a very different picture from the one that prevailed just a few decades ago is a platitude. The approaches where native speaker norms are revered as the gold standard to be faithfully emulated, and where "[t]he learner is constructed as a linguistic tourist allowed to visit, but without rights of residence and required always to respect the superior authority of native speakers" (Graddol 2006: 83), do not find much favourable resonance nowadays. The native standard, especially at the level of pronunciation, which for decades seemed to be the logical and common-sense choice in terms of targets and teaching materials, is now viewed as a instrument of oppression, neo-colonialism, and destruction of the learner's cultural integrity, or at best as unrealistic, unteachable and simply unnecessary. Therefore, it is hardly surprising that various scholars have 
proposed schemes to liberate the modern lingua franca from the shackles of native speaker standards, and to offer foreign learners an alternative to traditional EFL in the shape of the more democratic EIL/ELF paradigm, where the foremost determinant of correctness is international intelligibility. One of the leading exponents of this trend is Jennifer Jenkins, whose seminal 2000 book on the phonology of English as an International Language sparked off a lively, and sometimes rather heated, debate about the norms, models and targets to be chosen in the pronunciation teaching process.

As part of the effort to minimise both the advantageous position of native vs. nonnative speakers and the size of the task faced by the latter group while acquiring English phonology, Jenkins (2000: 136-153; also 2007: 23-24) proposed the so-called Lingua Franca Core (LFC), i.e., a core of pronunciation features which-according to her empirical research into NNS-NNS interactions-are vital to international intelligibility, and which therefore need to be present in each speaker's phonetic output in order to ensure successful communication. On the other hand, those features that seem inconsequential to intelligibility are designated non-core, and therefore-so the argument goes-there is no need for non-native speakers to strive to emulate NS patterns in producing them. The core areas cover the consonantal inventory (except the interdental fricatives, where L1-derived substitutions are acceptable), appropriate vowel length and tonic (nuclear) stress. The non-core features include vowel quality, weak forms (which can actually be counterproductive to intelligibility) and word stress.

The key idea underlying the ELFish proposals and manifestos is succinctly conveyed in the following assertion:

we are witnessing the emergence of an endonormative model of lingua franca English, which will increasingly derive its norms of correctness and appropriacy from its own usage rather than that of the UK or the US, or any other 'native speaker' country. (Seidlhofer 2001: 15).

Seidlhofer is the founding director of VOICE, i.e., the Vienna-Oxford International Corpus of English, an ongoing project aimed at collecting data on face-to-face ELF communication among fairly fluent speakers from a wide range of L1 backgrounds, in an attempt to provide an adequate description of how they use, or-in her own words-"rather co-construct, 'English' " while interacting (2002: 296). The project's official website (as of February 2010) announces that the corpus currently comprises 1 million words, equivalent to about 120 hours of transcribed speech, obtained from approximately 1250, mostly European, ELF speakers representing 50 different native languages.

The long-term objectives of the LFC/VOICE-like endeavours, however, go beyond a simple description and identification of core areas. It is argued that various linguistic forms peculiar to the ELF-as opposed to ENL (English as a Native Language)-mode of communication, as well as certain general strategies employed by NNSs in their interactions, could become codified and then make inroads into English dictionaries and grammar books. Therefore, ELF discourse, rather than being merely an interesting and somewhat amusing new phenomenon, could potentially provide norms for English language teaching, and consequently "be offered as a pedagogic alternative to (but not necessarily a replacement for) traditional EFL" (Jenkins 2007: xii). ELF advocates insist that ELF should be viewed and appreciated in its own right, rather than in comparison to ENL, as these are: "distinct, essentially different entities serving different functions" 
(Seidlhofer 2005: 59). This in itself is indicative of the fact that two codes may slowly be taking divergent routes of development, which in turn would foreshadow a bilingual relationship between them. This is consistent with Jenkins's (2000) prediction that

for future children, $[E I L]$ can be incorporated into the secondary school curriculum as a compulsory component of their existing English studies, and alongside the learning of other languages [...] [but] for those who have already reached adulthood it will be necessary to attend adult EIL classes

in order to speak internationally acceptable English.

One cannot help get the impression that the proposals for a codification of ELF look like attempts to make English a new Latin: create a contemporary, English equivalent of Medieval (Learned) Latin, in the spirit of the Carolingian Renaissance, which delivered Latin from its native speakers. After all, a critical step towards the split between LNL and LIL was the elaboration of a new pronunciation standard which deliberately ignored native speaker usage of the time. It is too early to tell whether the conceptual split of this kind will take root in the case of English. What seems to be evident at present is that the idea of English ultimately diverging into ENL and ELF-rather than into British, American, Australian, etc.-is no longer dismissed as fanciful. Rajagopalan goes even further and concludes that the split in question has already happened, in that English has already been supplanted by another language as the world's lingua franca. This new tongue, which he terms simply "World English", deserves to be "considered truly international precisely for not belonging exclusively to this or that nation" (2009: 52). This is reminiscent of Widdowson (1994: 385) much quoted assertion that:

The very fact that English is an international language means that no nation can have custody over it. To grant such custody of the language, is necessarily to arrest its development and so undermine its international status. [...] An international language has to be an independent language.

Admittedly, native speakers are rather uncomfortable to the concept of the global language of humankind, which should, after all, be common property. The existence of a group of users generally regarded as the standard setters, may be considered a weaknessrather than an advantage-of English (mis)cast in this role, in comparison to an artificial language like Esperanto. An international language would ideally be (an) "outil commode, bon pour toutes mains" (Meillet (1928/2004: 273), precisely in the way in which Medieval Latin has always been viewed. Therefore, learners who are only interested in acquiring English in its unique function as a communicative tool may welcome the arrival of a fully-fledged ELF pedagogic alternative with a feeling of relief. This may happen especially in countries where resentment of English cultural and linguistic imperialism is particularly deep.

Native speakers seem to become finally aware of the ongoing changes. Recent years have witnessed a substantial shift in the attitude towards ELF on the part of the anglophone linguist community: from that displayed by Trudgill (2002: 150f), who regarded the peculiarities of EIL usage as an amusing and totally benign phenomenon, to the previously mentioned concerns expressed by Graddol (2006: 11) over the appearance of a challenger for the position of dominance on the ELT scene: 
this is not English as we have known it, and have taught it in the past as a foreign language. It is a new phenomenon, and if it represents any kind of triumph it is probably not a cause of celebration by native speakers.

\section{Conclusion}

A commonplace statement that may serve well as an introduction to the conclusion here is that the beginning of the $21^{\text {st }}$ century is a time of rapid transformations and painful transitions, and the ELT world is no exception. I have attempted to demonstrate that the schemes to standardise English as a Lingua Franca along non-native lines may make the fate of foreigners' English similar to the fortunes of Medieval Latin, an easy-going international language which had thrown off the shackles of native speaker standards. One crucial question remains: is making English a new Latin a good or a bad thing? I wish to conclude by presenting two seemingly divergent views on the subject. Wright, specifically adopting the Latin-English perspective, offers a word of caution in this context:

if a standardized lingua franca were somehow able to adapt with the times, keep a close connection with the usages of all the native speakers who have no need to take any notice of such international standards, and remain more or less the same all over the world [...] it might just avoid leading to the main unfortunate consequences that followed from the adoption of standardized Medieval Latin. (Wright 2004: 10)

On the other hand, Modiano (2001: 344) seems to regard the emancipation of English as an International Language as a way to salvage the viability of ELT in general:

The teaching and learning of a geographically, politically, and culturally 'neutral' form of English, which is perceived as a language of wider communication and not as the possession of native speakers, is one of the few options we have at hand if we want to continue to promote English language learning while at the same time attempting to somehow 'neutralize' the impact which the spread of English has on the cultural integrity of the learner.

Needless to say, time will show whether making English a new Latin-if successful-will represent the ultimate victory or the beginning of demise of the English language teaching tradition.

\section{References}

Baugh, A. C. and T. Cable. 2002 (reprint). A History of the English Language. London: Routledge.

Bocheński, J. 2004. Łacina i noster [Latin and noster]. Gazeta Wyborcza 4-5.12.2004, 24-25.

Bragg, M. 2004. The Adventure of English. London: Hodder and Stoughton.

Chambers, J. K. and P. Trudgill. 1998. Dialectology. Cambridge: Cambridge University Press. 
Crystal, D. 1997. English as a Global Language. Cambridge: Cambridge University Press.

Dressler, W. U. 1996. Language Death. In Singh, R. (ed.), Towards a Critical Sociolinguistics. Amsterdam: Benjamins. 64-81.

Farrell, J. 2001. Latin Language and Latin Culture. Cambridge: Cambridge University Press.

Fisiak, J. 2000. An Outline History of English. Vol. 1: External History. Poznań: Wydawnictwo Poznańskie.

Graddol, D. 1997. The Future of English? London: British Council.

Graddol, D. 2006. English Next. Retrieved from http://www.britishcouncil.org/files/documents/learning-research-english-next.pdf.

Jenkins, J. 2000. The Phonology of English as an International Language. Oxford: Oxford University Press.

Jenkins, J. 2007. English as a Lingua Franca: Attitude and Identity. Oxford: Oxford University Press.

Lewis, M. P. (ed.). 2009. Ethnologue: Languages of the World. Dallas, Tex.: SIL International. Online version: http://www.ethnologue.com/.

Lexicon Recentis Latinitatis. Retrieved from http://www.vatican.va/roman_curia/institutions_connected/latinitas/documents/rc_lat initas 20040601 lexicon it.html.

Mackey, W. F. 2003. Forecasting the fate of languages. In Maurais, J. and M. A. Morris (eds.), Languages in a Globalising World. Cambridge: Cambridge University Press. 64-81.

Master, P. 1998. Positive and negative aspects of the dominance of English. TESOL Quarterly. 32, 716-727.

Meillet, A. 1928/2004. Esquisse d'une Histoire de la Langue Latine [An Outline History of the Latin Language]. Paris: Klincksieck.

Milroy, J. 2001. Received Pronunciation: Who "receives" it and how long will it be "Received"? Studia Anglica Posnaniensia 36, 15-33.

Modiano, M. 2001. Linguistic imperialism, cultural integrity, and EIL. ELT Journal 55/4, 339-346.

Orbis Latinus. Retrieved from http://www.orbilat.com/Languages/Latin/Latin.html.

Pope, M. K. (1953/1973). From Latin to Modern French with Special Consideration of Anglo-Norman. Manchester: Manchester University Press.

Rajagopalan, K. 2009. 'World English' and the Latin analogy: where we get it wrong. English Today 98, 49-54.

Seidlhofer, B. 2001. Towards making 'Euro-English' a linguistic reality. English Today 68, 14-16.

Seidlhofer, B. 2002. The shape of things to come? Some basic questions about English as a Lingua Franca. In Knapp, K. and C. Meierkord (eds.), Lingua Franca Communication. Frankfurt a/M: Peter Lang. 269-302.

Seidlhofer, B. 2005. Language variation and change: the case of English as a Lingua Franca. In Dziubalska-Kołaczyk, K. and J. Przedlacka (eds.), English Pronunciation Models: A Changing Scene. A Democratic Accent for the Global Village? Frankfurt a/M: Peter Lang. 59-75. 
Seidlhofer, B. 2006. English as a Lingua Franca in the Expanding Circle: What it Isn't. In Rubdy, R. and M. Saraceni (eds.), English in the World. Global Rules, Global Roles. London: Continuum. 40-50.

Trudgill, P. 2001. Received Pronunciation: Sociolinguistic aspects. Studia Anglica Posnaniensia 36, 3-13.

Trudgill, P. 2002. Sociolinguistic Variation and Change. Washington, D.C.: Georgetown University Press.

VOICE CORPUS. Retrieved from http://www.univie.ac.at/voice/page/corpus_description.

Widdowson, H. G. 1994. The ownership of English. TESOL Quarterly 28/2, 377-389.

Wright, R. 2002. A Sociophilological Study of Late Latin. Turnhout: Brepols.

Wright, R. 2004. Latin and English as world languages. English Today 80, 3-19. 